UNIVERSIDADE DE BRASÍLIA

FACULDADE DE CIÊNCIAS DA SAÚDE

NÚCLEO DE ESTUDOS EM EDUCAÇÃO E PROMOÇÃO DA SAÚDE

IV ESPECIALIZAÇÃO EM EDUCAÇÃO E PROMOÇÃO DA SAÚDE TURMA 2009

\title{
Promovendo a Saúde no Tratamento de CONSTIPAÇÃO DOS IDOSOS
}

\author{
JULIANA PINHEIRO GOMES
}

Brasília - DF

2009 
UNIVERSIDADE DE BRASÍLIA

FACULDADE DE CIÊNCIAS DA SAÚDE

NÚCLEO DE ESTUDOS EM EDUCAÇÃO E PROMOÇÃO DA SAÚDE

IV ESPECIALIZAÇÃO EM EDUCAÇÃO E PROMOÇÃO DA SAÚDE TURMA 2009

\title{
Promovendo a Saúde no Tratamento de CONSTIPAÇÃO DOS IDOSOS
}

\author{
JULIANA PINHEIRO GOMES \\ Monografia apresentada ao IV Curso de \\ Especialização em Educação e Promoção \\ da Saúde, sob orientação da Professora \\ Ms. Iraci Gonçalves Guimarães
}

Brasília - DF

2009 


\section{SUMÁRIO}

1 INTRODUÇÃO 4

2 REFERENCIAL TEÓRICO 6

2.1 Contribuição do Farmacêutico para a Promoção da Saúde 6

2.2 Constipação 8

2.2.1 Definição

2.2.2 Diagnóstico 9

$\begin{array}{lll}2.2 .3 & \text { Fisiopatologia } & 11\end{array}$

$\begin{array}{lll}2.2 .4 & \text { Causas } & 12\end{array}$

$\begin{array}{lll}2.2 .5 & \text { Epidemiologia } & 14\end{array}$

2.2.6 Complicações 15

$\begin{array}{lll}2.2 .7 & \text { Tratamento } & 16\end{array}$

$\begin{array}{lll}2.3 & \text { Lactulose } & 20\end{array}$

2.4 Fibras Sintéticas $\quad 21$

2.5 Custo do Tratamento 23

3 JUSTIFICATIVA 24

4 OBJETIVO 25

4.1 Objetivo Geral 25

4.2 Objetivos Específicos 25

5 METODOLOGIA 26

6 RESULTADOS 26

$\begin{array}{lll}6.1 & \text { Lactulose } & 27\end{array}$

6.2 Policarbofila Cálcica (Fibras Sintéticas) 28

7 DISCUSSÃO E CONCLUSÃO 31

8 REFERÊNCIAS BIBLIOGRÁFICAS 34 


\section{INTRODUÇÃO}

A partir dos alimentos são obtidas grandes quantidades de nutrientes, essenciais para o normal funcionamento do organismo. Os alimentos são, também, as fontes de energia para a realização das reações químicas em cada célula. Porém, para terem essas funções, esses devem ser primeiramente divididos em moléculas diminutas, suficientes para atravessar as membranas plasmáticas das células. Para que ocorra esta decomposição é realizado o processo de digestão, seguido pela absorção destas mesmas moléculas para o sangue e a linfa. Estas funções são executadas pelos órgãos que compõem o sistema digestório. Este sistema é formado pelo trato gastrintestinal e pelos órgãos digestórios acessórios. O trato gastrintestinal recebe o alimento no momento da ingesta e o contém até que seja digerido e absorvido, ou eliminado. As contrações musculares da parede do trato gastrintestinal empurram o alimento ao longo de todo o sistema, do esôfago até o ânus, para que o mesmo seja eliminado. ${ }^{1}$

No processo denominado defecação são eliminados materiais denominados como fezes, que incluem substâncias indigeríveis, resíduos, bactérias, materiais digeridos que não foram absorvidos e células desprendidas do revestimento do trato gastrintestinal. O reflexo da defecação inicia-se com a distensão causada pelas fezes na parede do reto, que estimula os receptores de estiramento, causando o esvaziamento do reto. É um processo auxiliado pela contração abdominal e pela força dos movimentos expiratórios contra a glote fechada, denominados manobra da Valsalva (expiração forçada com a glote presa). A defecação é um comportamento complexo que inclui tanto ações reflexas quanto voluntárias. ${ }^{2,3}$

O fenômeno do envelhecimento gera mudanças no sistema digestório que incluem a diminuição da motilidade dos órgãos digestórios, perda da força e tônus do tecido muscular e suas estruturas de sustentação, redução dos mecanismos secretores e diminuição da resposta à dor e sensações internas. No intestino grosso, em particular, pode ser observado o surgimento da constipação. ${ }^{1}$

A constipação significa o movimento lento das fezes ao longo do intestino grosso e está relacionada à defecação infreqüente, difícil ou incompleta, causada pela diminuição da motilidade dos órgãos digestórios. Com a permanência prolongada das fezes no colo ocorre a absorção excessiva de água, tornando-as secas e duras e, conseqüentemente, difíceis de expelir. Esta deficiência no peristaltismo acontece com o avanço da idade e, por sua vez, pode ser gerada por diversos fatores. A prevalência da constipação diverge entre os diversos estudos, pesquisas realizadas com a população norte-americana relatam que um quarto da 
população de idade entre 65 e 93 anos apresentam constipação crônica; e em outros estudos a prevalência relatada varia entre $19.2-40.1 \%{ }^{1,4}$

Dentre as possíveis causas da constipação estão os hábitos deficientes (defecação demorada em conseqüência da inibição dos reflexos normais), espasmos do colo, aderências que causam constrição do intestino, úlceras, desordem da função anorretal como resultado de um distúrbio neurogastroenterológico, insuficiência de fibra na dieta, ingesta inadequada de líquido, ausência de exercícios, estresse emocional e certos compostos químicos (constipação medicamentosa). ${ }^{5,6}$

As manifestações clínicas de tal patologia incluem: distensão abdominal, borborigmos (ruídos intestinais), dor e pressão, apetite diminuído, dor de cabeça, halitose, mal-estar, fadiga, indigestão, sensação de esvaziamento incompleto, força ao evacuar e eliminação de pequeno volume de fezes duras e secas.

Nos idosos, a constipação resulta de uma combinação de fatores de risco, tais como: reduzida ingestão de fibras e líquidos; diminuição da atividade física; doenças crônicas (diabetes mellitus, doença de Parkinson, depressão) e do uso de múltiplos medicamentos.

A partir da constatação do problema é preciso avaliar se há alguma doença grave associada ou se há necessidade de intervenção cirúrgica. Se não for nenhum dos dois casos, recomenda-se o tratamento clínico. O tratamento não-farmacológico, principalmente para idosos é o de primeira escolha, a fim de evitar o uso abusivo de laxantes. Assim, recomendase o aumento da ingestão de fibras (cereais, frutas, vegetais), de líquidos e realização de atividades físicas de rotina para fortalecer os músculos abdominais; tais medidas podem reduzir em $68 \%$ a probabilidade de relato de constipação. Quando o paciente não segue corretamente as medidas dietéticas ou comportamentais, ou as mesmas não desencadeiam efeitos satisfatórios, pode-se recorrer ao uso de laxantes, enemas e supositórios. ${ }^{7,8}$

$\mathrm{Na}$ prática farmacêutica, em que a preocupação com o bem estar do paciente representa a essencialidade das ações; o farmacêutico assume papel fundamental, somando seus esforços aos dos outros profissionais de saúde e aos da comunidade para a promoção da saúde. Ao promover a saúde, o farmacêutico promove o uso racional de medicamentos, define a melhor farmacoterapia, assegura a adesão ao tratamento e educa para o comprometimento do paciente com um comportamento saudável de vida. ${ }^{9,10}$

Assim, a escolha da farmacoterapia ideal para o tratamento da constipação intestinal em idosos, analisando a eficácia, a efetividade e eficiência da lactulose e das fibras sintéticas, comparando os seus perfis terapêuticos, permite traçar o melhor tratamento para a constipação em pacientes idosos; o que, conseqüentemente, contribui para a promoção da saúde. 


\section{REFERENCIAL TEÓRICO}

\subsection{Contribuição do Farmacêutico para a Promoção da Saúde}

A prevenção e o tratamento de doenças exigem infra-estrutura adequada, assim como educação apropriada. Após estas medidas, os medicamentos e as vacinas têm o potencial de conferir grandes benefícios à população. No entanto, o simbolismo de que se revestem os medicamentos na sociedade tem contribuído para a sua utilização irracional. Cabendo ao profissional farmacêutico promover a saúde; contribuindo assim, para a melhoria da utilização dos medicamentos pela sociedade. ${ }^{11}$

Sabe-se que a atividade farmacêutica no século XX passou por três períodos, definidos como: o tradicional, o de transição e o de desenvolvimento da atenção ao paciente. O papel tradicional foi desenvolvido pelo boticário que preparava e vendia os medicamentos, fornecendo orientações aos seus clientes sobre o uso dos mesmos. Era comum prescrevê-los. Conforme a indústria farmacêutica começou a se desenvolver, este papel do farmacêutico paulatinamente foi diminuindo. Começa assim o período de transição. As atividades farmacêuticas voltaram-se principalmente para a produção de medicamentos numa abordagem técnico-industrial.

A publicação da Lei 5.991/73, que ainda está em vigor, conferiu às atividades farmacêuticas um enfoque mercantilista. Qualquer empreendedor pode ser proprietário de uma farmácia ou drogaria, desde que conte com um profissional farmacêutico que se responsabilize tecnicamente pelo estabelecimento. Este é o marco da perda do papel social desenvolvido pela farmácia. O estabelecimento comercial farmacêutico voltou-se para o lucro e o farmacêutico começou a perder autonomia para o desempenho de suas atividades. $\mathrm{O}$ profissional passou a atuar como mero empregado da farmácia ou drogaria, perdeu o respeito da sociedade e refugiou- se em outras atividades, distanciando-se de seu papel de agente de saúde. Com isto, ampliaram-se os espaços para a obtenção de lucros desenfreados através da “empurroterapia" e da propaganda desmedidas. ${ }^{12,13,14,15}$

Mas, enfim, o farmacêutico em meio a uma grave crise de identidade iniciou sua reação fazendo nascer nos anos 60 a prática da farmácia clínica ${ }^{16}$. Esse profissional passou a se conscientizar do seu papel para a saúde pública. A prática farmacêutica começou a orientar-se para a atenção ao paciente e o medicamento passou a ser visto como um meio ou instrumento para se alcançar um resultado, seja este paliativo, curativo ou preventivo. Ou seja, a finalidade do trabalho deixou de focar o medicamento e passou a ser direcionado ao 
paciente, com a preocupação de que os riscos inerentes à utilização deste produto fossem minimizados.

O lamentável desastre ocorrido em 1962, em virtude do uso da talidomida por gestantes, ocasionando uma epidemia de focomelia, desencadeou um novo olhar sobre o uso dos medicamentos e foi o marco para o surgimento das ações de farmacovigilância. ${ }^{17}$

Os países começaram a se preocupar com a promoção do uso racional dos medicamentos, motivados pela publicação de documentos pela Organização Mundial da Saúde (OMS).

Dentro deste novo contexto da prática farmacêutica, no qual a preocupação com o bem estar do paciente passa a ser o norteador das ações, o farmacêutico assume papel fundamental, somando seus esforços aos dos outros profissionais de saúde e aos da comunidade para a promoção da saúde.

O farmacêutico promove a saúde assegurando o uso racional dos medicamentos, de forma que os pacientes recebam os medicamentos para a indicação apropriada, nas doses, via de administração e duração apropriadas; que não existam contra-indicações; que a probabilidade de ocorrência de reações adversas seja mínima; que a dispensação seja correta e que haja adesão ao tratamento. ${ }^{18}$

Sabe-se que os serviços farmacêuticos de atenção primária contribuem para a diminuição da internação ou do tempo de permanência no hospital, contribuem para a assistência aos portadores de doenças crônicas, para a prática de educação em saúde e, para uma intervenção terapêutica mais custo-efetiva. ${ }^{19}$

Dentro desta lógica, o serviço de farmácia deve assumir papel complementar ao serviço médico na atenção à saúde. O paciente que sai do consultório com uma receita terá maior resolução de seus problemas se tiver acesso ao tratamento prescrito e se a prescrição atender à racionalidade terapêutica. Mas não é só isto. Também é necessário avaliar os fatores que potencialmente podem interferir em seu tratamento, como: hábitos alimentares, tabagismo, histórico de reações alérgicas, uso de outros medicamentos ou drogas, outras doenças, ou até mesmo a falta de adesão. Esta avaliação, com a possibilidade de intervenção visando à efetividade terapêutica, pode ser alcançada com a implantação da atenção farmacêutica.

O farmacêutico, via de regra, é o último profissional de saúde que tem contato direto com o paciente depois da decisão médica pela terapia farmacológica. Desta forma, torna-se co-responsável pela sua qualidade de vida. Tanto o usuário quanto o profissional devem ser vistos na totalidade do seu ser e por isso, os conceitos de pessoa, responsabilidade, respeito, 
verdade, consciência, autonomia e justiça devem ser interiorizados para modelar a conduta profissional. $^{20,21}$

Assim, a estruturação das ações de atenção farmacêutica dentro do serviço de farmácia constitui uma abordagem imprescindível para a promoção da saúde. Logo, o estudo comparativo do perfil terapêutico entre a lactulose e as fibras sintéticas para o tratamento de constipação nos idosos insere-se no contexto da promoção da saúde, pois permite prevenir o surgimento de problemas relacionados a medicamentos; assegura qualidade de vida aos pacientes e permite fornecer educação continuada aos demais profissionais de saúde assegurando a integração entre o farmacêutico e a equipe dos demais serviços de saúde.

\subsection{Constipação}

\subsubsection{Definição}

A definição de constipação tem sido proposta com base na freqüência das evacuações. Porém esta patologia divide-se, com uma sobreposição considerável, em questões de consistência das fezes (endurecidas e de eliminação dolorosa) e questões de comportamento defecatório (infreqüência, dificuldade para evacuar e esforço durante a evacuação). Embora as fezes endurecidas freqüentemente resultem em dificuldades na evacuação, fezes volumosas e de consistência normal também podem associar-se à constipação, particularmente em pacientes idosos com anormalidades anatômicas e em pacientes com um comprometimento da motilidade colorretal. ${ }^{22}$

A constipação é o efeito final de vários fatores: dieta insatisfatória, falta de exercício, anormalidades de motilidade e defeitos anatômicos, juntamente com as expectativas do paciente e fatores psicológicos. A definição de constipação, portanto, inclui os seguintes sinais e sintomas: evacuações infreqüentes (menos de três vezes por semana), dificuldade na defecação (esforço durante mais de $25 \%$ das evacuações ou sensação subjetiva de fezes endurecidas) ou sensação de evacuação intestinal incompleta. ${ }^{22,23}$

Podem ser delimitados dois tipos desta mesma patologia, a constipação aguda ou crônica. A constipação intestinal aguda é desencadeada, normalmente, durante ou após mudanças no hábito alimentar, pelo uso de fármacos (constipação medicamentosa), redução da atividade física, pela obstrução do intestino grosso, pelo suprimento insuficiente de sangue para o intestino grosso, por uma lesão nervosa ou medular, pela presença de um estado mórbido ou, até mesmo, durante uma viagem, devido à mudança do ambiente de costume. 
Nestes casos, após a correção dos fatores desencadeantes a constipação se resolve espontaneamente. Já a constipação intestinal crônica é classificada em funcional simples, funcional idiopática e orgânica. Neste caso, o ritmo evacuatório se mantém razoavelmente constante há pelo menos dois anos. ${ }^{24,25}$

A constipação intestinal funcional é caracterizada pela presença de fezes endurecidas na maioria das evacuações ou frequiência menor que duas vezes por semana, na ausência de doenças orgânicas. A constipação intestinal orgânica é observada mais freqüentemente em doenças: a Doença de Hirschsprung, malformação anorretal (estenose anal ou retal), Doença de Chagas, pseudo-obstrução intestinal, tumores, hipotiroidismo, hipocalemia, hipercalemia, espinha bífida, trauma, mielomeningocele, paralisia cerebral, doença celíaca, fibrose cística, entre outros. ${ }^{26,27}$

\subsubsection{Diagnóstico}

Por meio de um histórico cuidadoso podem-se explorar os sintomas dos pacientes e confirmar se os mesmos estão de fato constipados. Esta análise deve ser feita baseada na frequiência (menos de três movimentos intestinais por semana), consistência das fezes, força excessiva durante a evacuação, tempo de defecação prolongado e sensação de esvaziamento incompleto do reto. Provavelmente em mais de $90 \%$ dos casos não há causa subjacente, como o câncer, depressão ou hipotiroidismo; e a constipação pode ser tratada com ampla hidratação, exercícios e suplementação com dieta de fibras. ${ }^{6}$

Diante da ampla faixa dos hábitos intestinais considerados normais é difícil definir precisamente a ocorrência da constipação. A maior parte das pessoas tem pelo menos três movimentos do intestino por semana; entretanto, a freqüência das evacuações isoladamente não é suficiente como critério de diagnóstico. Isso ocorre porque muitos pacientes constipados apresentam uma freqüência de defecação normal, porém outros sintomas como força excessiva no ato, fezes duras, trânsito abdominal lento, e uma sensação de evacuação incompleta. Por exemplo, no caso dos indivíduos que evacuam mais de três vezes por semana, porém eliminam fezes em quantidade muito pequena, ou fazem esforço para evacuar ou apresentam somente queixa de dor abdominal recorrente, observa-se a constipação definida como oculta. ${ }^{6,26}$

Mais recentemente, uma definição consensual foi desenvolvida, baseada nos critérios quantitativos que avaliam dificuldades na defecação e a freqüência de evacuação (Critério 
Roma II). O diagnóstico requer a presença de dois ou mais sintomas relatados abaixo, por pelo menos três meses, consecutivos ou não, no último ano:

a) Esforço em pelo menos $25 \%$ das evacuações.

b) Fezes endurecidas ou fragmentadas em pelo menos $25 \%$ das evacuações.

c) Sensação de evacuação incompleta em pelo menos $25 \%$ das evacuações.

d) Sensação de obstrução ou interrupção da evacuação em pelo menos $25 \%$ das evacuações.

e) Manobras manuais para facilitar em pelo menos $25 \%$ das evacuações.

f) Menos de 3 evacuações por semana. ${ }^{28}$

A adoção de uma definição padrão de constipação é especialmente importante dado à discordância com as definições relatadas pelos próprios pacientes idosos. Por exemplo, em um grande estudo epidemiológico americano, em $37 \%$ das mulheres e em 59\% dos homens que cumpriram os critérios do Roma II não relatavam constipação antes de participarem de tal estudo. A situação torna-se mais complexa nos casos em que o paciente não relata sintomas de constipação, mas usa laxantes de forma regular. Todavia, é essencial definir precisamente a natureza dos sintomas em pacientes idosos que se queixam de constipação. Aplicar esta definição padrão e usar critérios quantitativos é uma primeira etapa necessária para determinação da conduta médica. ${ }^{8}$

$\mathrm{Na}$ anamnese é importante abordar o relato do início do problema, a dieta seguida, a presença de outros sinais e sintomas, outras doenças orgânicas associadas e o uso de medicamentos.

Os sintomas de cada paciente devem, portanto, ser analisados criteriosamente para distinguir o que de fato é considerado constipação ou uma dificuldade quanto à defecação.

Ao exame físico é importante verificar a presença de distensão abdominal e de massas fecais, realizar a inspeção da região perineal, verificando a presença de fissuras e estenose anal e realizar o toque retal. É possível observar uma diminuição da sensibilidade da mucosa anal à distensão e diminuição da contratilidade retal. O toque retal, além de afastar possíveis causas orgânicas, permite uma avaliação inicial do estado funcional do aparelho esfincteriano e do esvaziamento retal. Este exame deverá ser feito em repouso, durante contração voluntária do esfíncter e até mesmo durante o esforço evacuatório, quando distúrbios poderão ser diagnosticados ou suspeitados. ${ }^{26,27}$ 


\subsubsection{Fisiopatologia}

As principais funções do colo são absorver água e eletrólitos e conduzir as fezes desde o intestino delgado até o sigmóide, onde são armazenadas antes das evacuações. Após as refeições podem ocorrer contrações colônicas de grande amplitude, denominadas reflexo gastro-cólico, que se propagam a partir do sigmóide proximal em direção a sua porção terminal, empurrando a massa fecal para o interior do reto. O reflexo da defecação se inicia com a chegada do bolo fecal na ampola retal, gerando a dilatação do reto e, conseqüentemente, estimulando os receptores sensíveis ao estiramento localizados na região. A partir destes receptores é determinado o relaxamento do esfíncter anal interno, processo conhecido como reflexo reto anal. Com isso, é permitido que o conteúdo retal seja percebido de modo discriminado para gases, líquidos ou fezes pastosas. Neste momento, o indivíduo pode decidir pela contração voluntária do esfíncter externo até chegar ao local apropriado para defecar. ${ }^{24}$

A continência fecal depende do perfeito funcionamento do esfíncter anal externo, do músculo puborretal, do esfíncter anal interno e do reto. Para a evacuação, a posição ideal é equivalente ao agachado, com contração da musculatura abdominal durante a inspiração, relaxamento do esfíncter externo do ânus e contração do músculo elevador do ânus.

Se a vontade de evacuar for ignorada, a mucosa retal e a musculatura tornam-se insensíveis à presença de massa fecal, e, conseqüentemente, é necessário um grande estímulo para produzir o ímpeto peristáltico necessário para a defecação. O efeito inicial da retenção fecal é produzir irritabilidade do cólon, que, nesse ponto, freqüentemente leva a um espasmo, sobretudo após as refeições, fazendo surgir dores no baixo e no médio abdome, tipo cólica. Se a tal processo perdurar por vários anos, o cólon gradativamente perde o tônus muscular e passa a não responder normalmente ao estímulo.

Os idosos particularmente apresentam um risco mais acentuado de desenvolverem constipação crônica, pois com o avanço da idade ocorre atonia ou diminuição do tônus muscular, assim como, os movimentos intestinais diminuem gradativamente, ficando as fezes retidas por um longo período de tempo no reto (retenção fecal). Com isso, o reto passa a conter as fezes, progressivamente mais ressecadas e em maior volume. A parede retal torna-se cronicamente dilatada e a sensibilidade retal diminui, logo estes indivíduos tornam-se menos responsivos ao estímulo de evacuação. 


\subsubsection{Causas}

Existem as causas auto-induzidas para o fenômeno da constipação, mais freqüentes e geralmente associadas à ingestão insuficiente de fibras, inatividade física, lesão dos nervos do colo, pelo uso crônico e abusivo de laxantes ou retenção voluntária e não obediência ao reflexo da evacuação. Em resumo, estão relacionadas a hábitos alimentares e comportamentais inadequados.

As causas ambientais geram a constipação transitória, que pode ser resolvida assim que a condição desfavorável é removida. Trata-se de condições momentâneas como a indisponibilidade de um banheiro, condições desfavoráveis de trabalho ou viagem, ou os casos de pacientes acamados pela imobilidade. É bastante comum identificar indivíduos que só conseguem evacuar em casa. Esse adiamento constante da evacuação reduz a sensibilidade do intestino, e como as fezes permanecem mais tempo no intestino, ocorre maior absorção de água, levando ao seu ressecamento.

A idade avançada também pode ser causa da constipação intestinal diante das alterações na estrutura e na função do cólon no envelhecimento, tais como: diminuição da flexibilidade retal, diminuição do reconhecimento do ímpeto para evacuar, diminuição da pressão latente e compressão do canal anal. Contudo, o envelhecimento por si só não causa a constipação; a elevada incidência de constipação na população idosa resulta de uma combinação de fatores de risco, como por exemplo: ingestão reduzida de líquidos e de fibras; diminuição na prática de exercícios físicos, doenças crônicas (Tabela 1) e utilização de vários medicamentos - polifarmácia (Tabela 2). No caso dos idosos acamados e internados deve-se ter uma atenção especial, pois a ausência de atividade e o decúbito prolongado causarão uma diminuição da atividade do intestino grosso.

Por último, observam-se as causas idiopáticas, ou seja, de origem desconhecida. Como, por exemplo, os distúrbios motores do megacólon chagásico e não chagásico. 
Tabela 1 - Estados de saúde relacionados com a constipação em pessoas idosas.

\begin{tabular}{ll}
\hline Sistema do Organismo & Patologia \\
\hline Gastrointestinal & Neoplasia \\
& Retocele \\
& Prolapso retal \\
& Rectocele \\
& Megacólon (Doença de Hirschsprung) \\
& Fissura Anal \\
& Compressão Externa de Lesão Malígna \\
& Síndrome do Intestino Irritável \\
& Diabetes mellitus \\
Endócrino e metabólico & Hipotiroidismo \\
& Distúrbios eletrolíticos \\
& \multicolumn{1}{c}{ Hipercalcemia } \\
& \multicolumn{1}{c}{ Hipocalemia } \\
Cardíaco & Uremia \\
Neurológico & Insuficiência Renal Crônica \\
& Insuficiência Cardíaca Congestiva \\
& Doença de Parkinson \\
& Doença Cerebrovascular \\
& Demência \\
Outras Condições & Depressão \\
& Medula espinhal (tumor, injúria) \\
& Esclerose Múltipla \\
& Desidratação \\
& Estado Acamado \\
&
\end{tabular}

BOSSARD Wanda; DREHER Rebeca; SCHNEGG Jean François; BÜLA Cristophe J. The Treatment of Chronic Constipation in Elderly People: an update. Drugs Aging. 2004; 21: 914-915.

LOCKE GR III; PEMBERTON JH; PHILIPS SF. American Gastroenterological Association Medical Position Statement: guidelines on constipation. Gastroenterology. 2000; 119:1761-1766. 
Tabela 2 - Medicações freqüentemente associadas com a constipação

\section{FÁRMACOS PRESCRITOS}

Analgésicos

Agentes Anticolinérgicos

Antidepressivos (antidepressivos tricíclicos)

Anti-histamínicos (difenidramina)

Antagonistas do Canal de Cálcio

Diuréticos

NSAIDS

Antipsicóticos

Fármacos Antiparkinsonianos

Simpaticomiméticos

\section{FÁRMACOS NÃO-PRESCRITOS}

Antiácidos (especialmente os que contêm cálcio)

Suplementos de Cálcio

Suplementos de Ferro

Agentes Antidiarreicos

AINES

\section{EXEMPLOS}

Morfina, tramadol, codeine

Librax, beladona

Nortriptilina, amitriptilina

Difenidramina

Verapamil

Furosemida, Hidroclorotiazida

Clorpromazina

Amantadina

Efedrina, terbutalina

BOSSARD Wanda; DREHER Rebeca; SCHNEGG Jean François; BÜLA Cristophe J. The Treatment of Chronic Constipation in Elderly People: an update. Drugs Aging. 2004; 21: 914-915.

LOCKE GR III; PEMBERTON JH; PHILIPS SF. American Gastroenterological Association Medical Position Statement: guidelines on constipation. Gastroenterology. 2000; 119:1761-1766.

\subsubsection{Epidemiologia}

Em conseqüência dos diversos conceitos utilizados no diagnóstico da constipação o coeficiente de prevalência de tal patologia em idosos é bastante variável. Em determinados estudos a prevalência citada varia entre 15 a $20 \%$ em idosos asilados; outros já relatam a prevalência variando entre 19.2 a 40.1\%; em algumas pesquisas com pacientes assistidos pelos serviços da enfermagem a prevalência é superior a $50 \%$ e em estudos baseados em relatos de idosos residentes em seus próprios domicílios a prevalência foi de 30\%. A partir de pesquisas, pode-se considerar que aproximadamente um em cada cinco ou seis pessoas idosas apresenta constipação. ${ }^{8,4}$

A elevada prevalência da constipação corresponde a um significativo problema de saúde na população idosa, associada dessa forma, com o prejuízo na qualidade de vida da mesma; estudos randomizados com idosos canadenses revelaram que para $11 \%$ dessa população a constipação é considerada o principal problema de saúde. ${ }^{8}$ 
Geralmente a constipação é relatada com mais freqüência por mulheres do que pelos homens; estudos americanos constataram que a prevalência da constipação em mulheres idosas (acima de 65 anos) é de 34\% e de 30\% para os homens idosos. De forma geral, os estudos encontraram taxas duas ou três vezes mais elevadas de constipação em mulheres idosas do que em homens; acredita-se que seja devido à diminuição da concentração plasmática de estrógeno após a menopausa. ${ }^{8,29,30}$

A constipação, como já citado, também é freqüente em pacientes idosos assistidos pelo serviço de enfermagem em seus domicílios. Metade desta população relata constipação e $74 \%$ desta mesma utiliza laxantes diariamente; e menos da metade dos pacientes que utilizam laxantes prescritos têm constipação diagnosticada. Neste último dado observa-se que ocorre a prescrição indevida de tais medicamentos e o uso abusivo dos mesmos pelos idosos, sendo a polifarmácia uma possível consequiência desses atos. Pois, sabe-se que para $54 \%$ dos pacientes idosos com constipação diagnosticada é prescrita a monoterapia e para os $46 \%$ restante é prescrito dois ou mais laxantes. ${ }^{8,31}$

Deve-se levar também em consideração os gastos financeiros, pois os idosos relatam uma proporção substancial de custos com laxantes prescritos e não prescritos, estimados em 43 milhões de euros por ano na Inglaterra, e acima de 500 milhões de dólares por ano nos Estados Unidos. O gasto anual encontrado por meio de estudos americanos realizados com o objetivo de determinar o custo do tratamento da constipação diagnosticada em idosos foi de 2.253 dólares anuais a cada paciente. ${ }^{8,32}$

\subsubsection{Complicações}

Quando a constipação intestinal não é tratada adequadamente pode evoluir, em longo prazo, para novas e grandes complicações, sendo mais freqüentes os seguintes quadros: diverticulose, hemorróidas, fissuras anais, incontinência fecal e câncer do intestino.

A diverticulose é caracterizada pela formação de saculações do revestimento interno do intestino para fora de suas paredes. As hemorróidas são dilatações tortuosas dos vasos sanguíneos da região anal, sendo que a passagem de fezes ressecadas por esta região ou o esforço exagerado ao evacuar podem causar o rompimento destes vasos. As fissuras anais correspondem a cortes na região anal, provocados por fezes ressecadas e esforço ao evacuar. A incontinência fecal surge decorrente da existência prolongada da constipação, pois o prolongado esforço evacuatório acarreta a descida excessiva do períneo e flacidez pélvica; assim, o reto não propulsiona o bolo fecal distalmente, sendo a conseqüência imediata o 
obstáculo à defecação, porém, a longo prazo, observa-se a incontinência fecal. O aumento do tempo do trânsito intestinal gera um conseqüiente maior contato de substâncias cancerígenas encontradas nas fezes com as paredes do intestino grosso, além de alterar a microbiota residente; por isso a constipação propicia um aumento na probabilidade de desenvolvimento de câncer no intestino.

\subsubsection{Tratamento}

Antes de introduzir qualquer tratamento, um cuidadoso histórico, incluindo a avaliação de fatores de risco, são necessários (Figura 1). Uma atenção particular deve ser dada à freqüência do movimento intestinal e aos sintomas da constipação, para evitar uma terapêutica exacerbada a pacientes que apresentam queixas sobre seus hábitos intestinais, mas não apresentam constipação clinicamente diagnosticada. Impacto retal recorrente, inchaço doloroso e esforço excessivo são certamente indicações para realização de tratamento.

Como mencionado previamente, a etapa inicial de conduta de tratamento da constipação no paciente idoso é substituir toda prescrição e OTCs que apresentem a constipação como efeito adverso (Vide tabela 2). Em adição, a obstrução mecânica deve ser excluída por exame pélvico e retal e, se necessário, solicitar raio-X abdominal. Uma vez que a obstrução é excluída, e na ausência de constipação severa, medidas não-farmacológicas são propostas. Estas medidas permanecem válidas também quando laxantes são introduzidos.

As medidas não farmacológicas incluem aumento na ingesta de fluido, atividade física regular e ingestão de elevada quantidade de fibra, que pode ser obtida a partir de determinados alimentos (Vide Tabela 3). Estudos prospectivos descrevem que a ingestão por um período de 6 meses de 12,8 gramas de fibras acarreta em um aumento de 57,1\% na função intestinal. Outras pesquisas americanas prospectivas relataram que a hidratação e a ingestão de fibras reduziram o consumo de laxantes de $90.2 \%$ para $40 \%$ em pacientes idosos com constipação diagnosticada. Tais medidas parecem ser apropriadas para idosos aptos a realizarem esse tipo de tratamento. ${ }^{33}$ 
Figura 1 - Algoritmo do tratamento da constipação crônica em pacientes idosos.

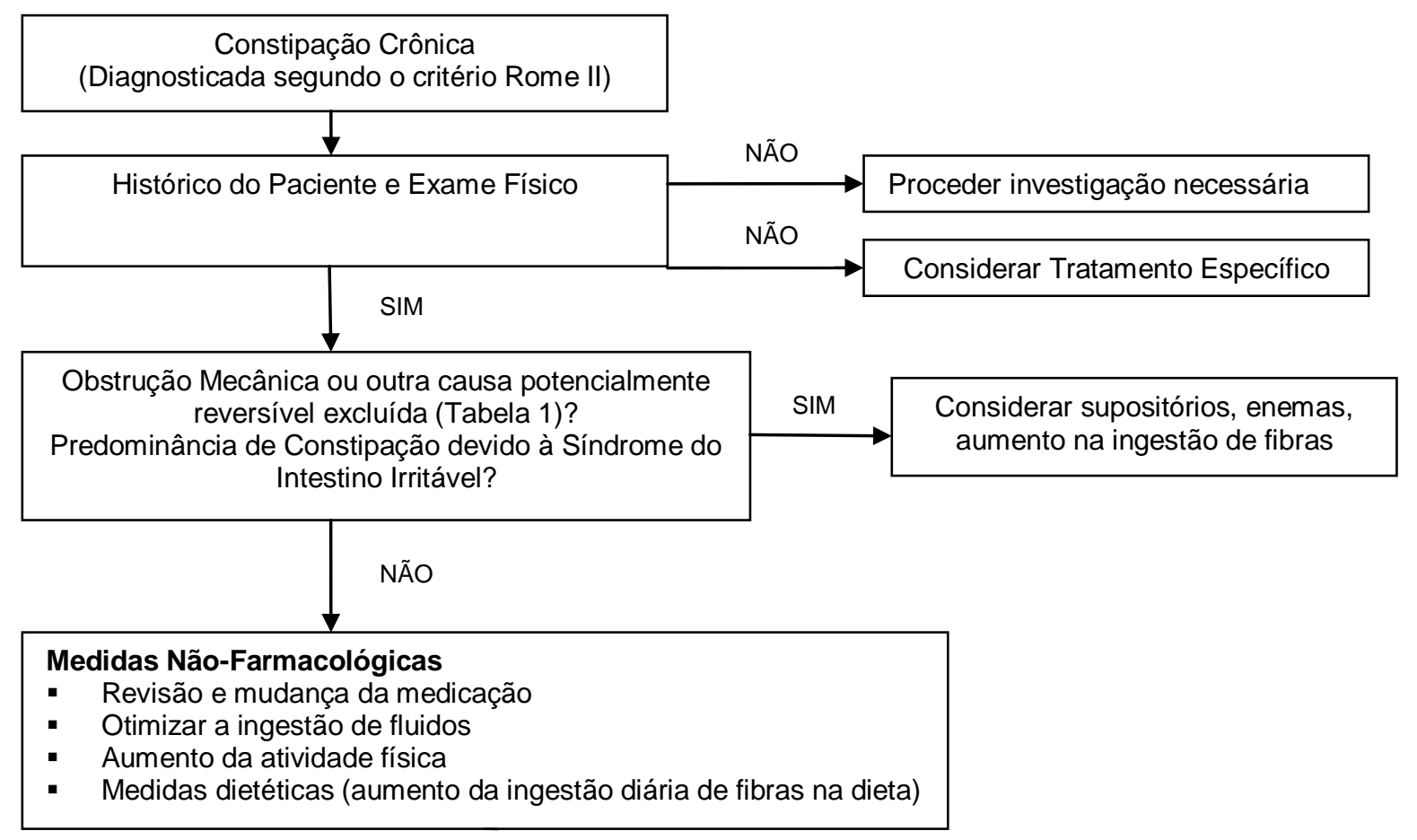

BOSSARD Wanda; DREHER Rebeca; SCHNEGG Jean François; BÜLA Cristophe J. The Treatment of Chronic Constipation in Elderly People: an update. Drugs Aging. 2004; 21: 914-915

Tabela 3 - Alimentos ricos em fibras.

Goiaba

Banana

Laranja

Maçã (com casca)

Pêra (com casca)

Ameixa

Hortaliças (brócolis)

Cenoura

Batata

Farelo de aveia

Nozes

Leguminosas (feijão, vagem, ervilha, lentilha)

Grãos de cereais (milho, soja, grão de bico, cevada)

Pão integral

KENNY K. A.; SKELLY J. M. Dietary fiber for constipation in older adults: a systematic review. Clinical Effectiveness in Nursing 2001; 5, 120-128. 
Os tratamentos farmacológicos podem ser considerados se tais medidas não aliviam a constipação. É possível recorrer ao uso de laxantes osmóticos (glicerina, lactulose), salino hiper-osmóticos (leite de magnésia), lubrificantes (óleo mineral), formadores de massa (metilcelulose, Psyllium) e estimulantes ou de contato (Cáscara Sagrada, Sene, bisacodil). ${ }^{21,22}$

Um dos possíveis tratamentos envolve o uso de supositórios de glicerina (laxante hiper-osmótico), que são inseridos através do ânus até o reto. A glicerina possui a propriedade de atrair a água, auxiliando no amolecimento das fezes para facilitar a defecação. ${ }^{3}$

O laxativo mais utilizado é o óleo mineral (laxante do tipo lubrificante) na dose de 3 $5 \mathrm{ml} / \mathrm{kg} / \mathrm{dia}$ e o hidróxido de magnésio (laxante salino hiper-osmótico) na dose de 1 - 3 $\mathrm{ml} / \mathrm{kg} /$ dia. Em idosos, o óleo mineral pode diminuir a absorção de vitaminas lipossolúveis, não sendo recomendado, portanto, seu uso prolongado.

No caso dos agentes osmóticos há o inconveniente do custo elevado e o risco de desenvolvimento de distensão e flatulência devido à fermentação destes açúcares pelas bactérias do cólon.

As fibras (laxantes formadores de massa) também constituem uma forma de tratamento para a constipação e consistem em carboidratos vegetais indigeríveis, como a celulose, lignina e pectina (presente na fibra de maracujá). São encontradas em frutas, vegetais, grãos e leguminosas. Existem as fibras naturais insolúveis, que têm menor capacidade de incorporação de água e passam pelo trato gastrintestinal inalteradas e aumentam a passagem de material ao longo do trato. Já as fibras naturais solúveis absorvem a água formando um gel, que retarda a passagem do material pelo trato, mantendo o volume líquido até a evacuação. Em ambos os casos, há a absorção de água gerando o aumento do volume fecal e a diminuição de sua consistência, facilitando a eliminação. 1,26

As fibras naturais apresentam alguns inconvenientes como a formação de gases e cólicas, devido à presença da fração solúvel da fibra. Também produzem uma sensação de estômago pesado e estufado, causado pela retenção de água pelas fibras, que incham e tornam mais viscoso o resíduo digestivo antes de sua chegada ao duodeno. Porém, foram criadas a partir de síntese química as fibras sintéticas, de característica insolúvel e que não apresentam os mesmos efeitos descritos para as fibras naturais.

Dentre as fibras naturais o polissacarídeo hidrofílico mais comumente utilizado é obtido a partir da espécie Plantago ovata, também denominada Ispaghula husk ou Psyllium. É comercializado sob forma de pó, que é obtido através da casca da semente seca da planta e é disponível em sua forma pura. 
Como exemplo de fibra semi-sintética, destaca-se a metilcelulose e como sintética, a policarbofila cálcica.

A recomendação da ingesta de fibras deve ser sempre acompanhada pela advertência do aumento no consumo de líquidos simultaneamente, até atingir 1,5 a 2 litros por dia. Pois a ingestão de fibras por idosos, que normalmente apresentam menor motilidade intestinal por conseqüência do avanço da idade, pode acarretar no acúmulo de grande quantidade de massa fecal sem que o organismo tenha a capacidade de promover a propulsão de tal massa. Assim, a ingestão de líquidos evita a formação de um bolo fecal sólido que se comporta como um obstáculo à defecação; evitando dessa forma, a impactação fecal e o conseqüente agravamento da constipação.

Os agentes formadores de massa atuam de forma lenta e suave e representam uma das formas mais seguras para promover evacuações regulares. Em geral, primeiramente esses agentes são administrados em pequenas quantidades e a dose é aumentada gradualmente até que ocorra regularização. ${ }^{24}$

Os estimulantes químicos, como o bisacodil, são derivados do polifenol e normalmente causam cólicas abdominais. ${ }^{26}$

A primeira escolha preconizada é um laxante formador de massa, desde que o paciente esteja disposto a tomar bastante líquido. Se não, ou no caso de falha, recomenda-se o uso de um laxante osmótico. ${ }^{8}$

Os laxantes estimulantes (exemplo Senne) devem ser prescritos aos pacientes que não responderam a primeira tentativa, como um tratamento intermitente, já que podem causar o cólon catártico. Essa patologia secundária é explicada pela lesão dos plexos mioentéricos, causada pela estimulação excessiva por estes laxantes. ${ }^{26}$ Dados adicionais são necessários para esclarecer o papel das drogas procinéticas. Finalmente, a combinação com enemas pode ser considerada em pacientes refratários às tentativas anteriores de tratamento.

O tratamento cirúrgico tem papel importante nos casos de obstrução da via de saída retal (retocele, prolapso retal, intussuscepção retal interna) ou em pacientes com cólon hipotônico (causado por laxantes) que já tenham sido submetidos ao tratamento clínico. No primeiro caso, a intervenção é dirigida à causa da obstrução da saída e, no segundo caso, poderá resultar em colectomia abdominal total. Porém, antes de qualquer procedimento cirúrgico irreversível é necessário analisar possíveis causas psicológicas adjacentes e utilizar mecanismos para abordá-las. ${ }^{34}$ 
Figura 2 - Algoritmo do tratamento farmacológico da constipação crônica em pacientes idosos.

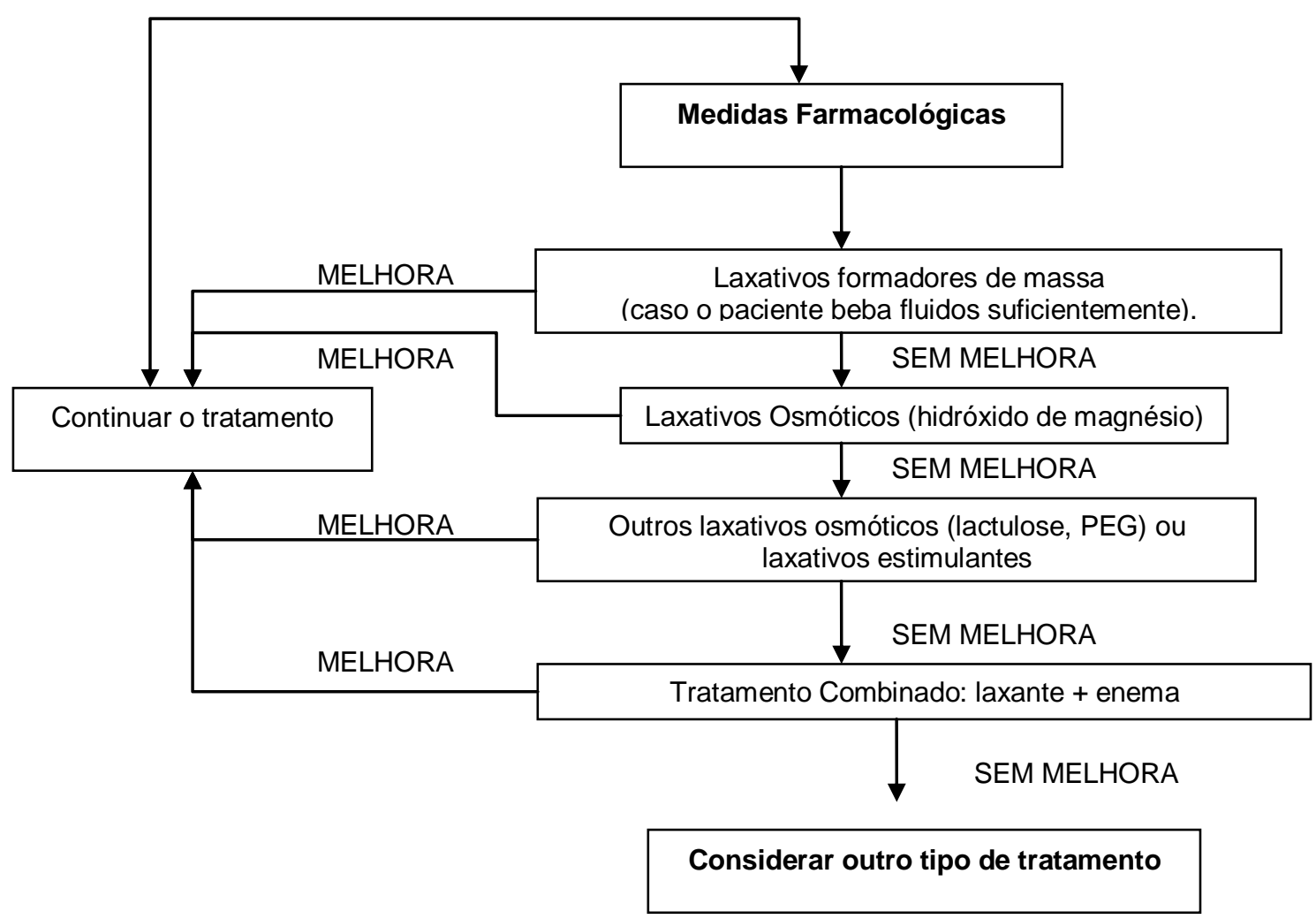

BOSSARD Wanda; DREHER Rebeca; SCHNEGG Jean François; BÜLA Cristophe J. The Treatment of Chronic Constipation in Elderly People: an update. Drugs Aging. 2004; 21: 914-915

Assim, independente do tratamento adotado devem ser dispensadas orientações gerais sobre a cronicidade da constipação intestinal, as informações sobre a correta postura a ser adotada no ato da defecação, a importância de uma maior ingesta de líquidos e fibras, deve ser encorajada a prática de exercícios físicos e, nos casos de comprometimento psicológico acentuado, é indispensável à colaboração do profissional especializado.

Como o objetivo da monografia é definir qual o melhor tratamento para a constipação em idosos comparando-se a lactulose com as fibras sintéticas; adiante será dada ênfase a estes dois tipos de tratamento, a fim de garantir embasamento teórico suficiente para realizar tal escolha.

\subsection{Lactulose}

Trata-se de um laxante hiper-osmótico, anti-hiperamonêmico, um dissacarídeo sintético e análogo da lactose. Seu mecanismo de ação baseia-se em provocar um aumento da 
pressão osmótica do meio a partir de sua metabolização em subprodutos ácidos e, com isso, acidificar o conteúdo do colo intestinal, fazendo com que as fezes tornem-se mais hidratadas e moles. Também diminui a concentração de amônia no sangue, pois a mesma migra para o cólon e é expelida pelas fezes. ${ }^{35}$

A lactulose deve ser administrada com o estômago vazio ou juntamente com algum alimento, a dose usual varia entre 15 a $30 \mathrm{~mL}$, podendo ser administrada em uma vez ao dia ou dividida em duas doses. As reações adversas decorrentes do uso da lactulose são: eructações, fortes cólicas abdominais, acidose lática, diarréia, gases e náuseas. Dentre as interações observadas destaca-se a capacidade de diminuir a ação de suplementos de potássio e diuréticos poupadores de potássio. Por conter pequenas quantidades de lactose e galactose e devido à possibilidade de absorção de tais açúcares, é contra-indicada para pacientes com dieta livre de galactose, com galactosemia ou obstrução intestinal; e seu uso deve ser monitorado em pacientes diabéticos e com intolerância à lactose. ${ }^{34,35,36}$

Uma vez ingerida, o efeito inicial é deflagrado entre 24 a 48 horas após a administração. A lactulose não é absorvida pelo trato gastrintestinal e nem hidrolisável pelas enzimas intestinais; devido à ausência de enzima específica (lactulase), chegando ao cólon praticamente inalterada, onde é fermentada pelas bactérias sacarolíticas, produzindo o ácido láctico e pequenas quantidades de ácido acético e fórmico (ácidos de baixo peso molecular) que atuam como laxantes. Logo, somente $3 \%$ da dose administrada é excretada sem nenhuma alteração pela urina. ${ }^{36}$

\subsection{Fibras Sintéticas}

A policarbofila cálcica, um tipo de fibra sintética, age como um laxante formador de massa, retendo a água livre do lúmen intestinal acarretando no aumento da pressão luminal; aumento do peristaltismo; diminuição do tempo de trânsito intestinal e formação do bolo fecal. Além de provocar menos cólicas e a formação de gases, também possui maior capacidade de retenção de água, se comparada às fibras naturais. Em relação ao Psyllium retém de três a quatro vezes maior quantidade de água e consegue absorver de 60 a 100 vezes a própria massa em água.

Trata-se de uma resina hidrofílica cuja dose usual são dois tabletes (mastigáveis), quatro vezes ao dia, associados a oito medidas de água (aproximadamente $230 \mathrm{~mL}$ ). A concentração máxima de cálcio por tablete é de 150 miligramas, sendo que os tabletes de 500 miligramas de policarbofila contêm 140 miligramas de cálcio. ${ }^{36}$ 
Nos casos de insuficiências renal, hepática ou de realização de diálise, não é necessário realizar o ajuste de dose, já que o fármaco não é absorvido. A resposta inicial após a ingesta do medicamento é deflagrada em 12 a 72 horas, quando o movimento intestinal é geralmente produzido. O uso da droga é contra-indicado nos casos de obstrução intestinal ou impactação fecal e não possui reações adversas documentadas já que a mesma não é absorvida, exceto em relação aos efeitos gastrintestinais, que podem variar de flatulências a cólicas. Também deve ser evitado o uso de antibióticos contendo tetraciclina ou derivados durante a administração da policarbofila, já que esta reduz a absorção do antibacteriano. Para solucionar este problema, a fibra deve ser ingerida 1 hora antes ou 2 horas depois da administração do antibiótico. ${ }^{36,37}$

Outro caso particular que deve ser considerado são os pacientes que possuem ingesta de cálcio restrita, pois a policarbofila pode liberar íons de cálcio no trato gastrintestinal. ${ }^{37}$

Sua metabolização não ocorre pelo organismo ou pela microbiota residente do colo, por isso não há a formação de substâncias gasosas como hidrogênio e metano ou produtos voláteis como o ácido acético, butírico e propiônico. Por ser um polímero sintético, a policarbofila não é degradada por enzimas digestivas ou bacterianas, sendo excretada integralmente nas fezes, sem nenhuma biotransformação.

As fibras naturais retêm a água independente do $\mathrm{pH}$ do meio em que se encontram, seja ácido, básico ou neutro. Por esta característica, estas fibras normalmente absorvem água, incham e aumentam sua viscosidade ainda no estômago, onde o pH é ácido, levando à sensação de empachamento gástrico. Já a policarbofila cálcica, em condições ácidas, absorve muito menos água, enquanto no intestino, onde o $\mathrm{pH}$ é básico, atinge seu poder hidrofílico total. Diante deste comportamento, percebe-se que a sensação de estômago pesado e estufado é minimizada.

A policarbofila cálcica é tão eficiente quanto o Psyllium no tratamento dos sintomas da constipação em pacientes idosos. Entretanto, a ocorrência de flatulências como efeito colateral é menor com o uso da policarbofila cálcica se comparada ao Psyllium. A policarbofila também tem maior adesão, pois sua forma farmacêutica (comprimidos) tem maior vantagem quanto à facilidade de ingesta se comparada às suspensões (Psyllium). ${ }^{36}$

Outro exemplo de fibra semi-sintética é a metilcelulose, que possui o mesmo mecanismo de ação da policarbofila e é usualmente efetivo entre 12 e 24 horas. Dentre suas características químicas apresenta baixa solubilidade em água quente, álcool, acetona e tolueno, e dissolve bem em água fria, formando uma solução coloidal. ${ }^{36,37}$ 
Grandes quantidades de metilcelulose podem aumentar temporariamente o desenvolvimento de flatulências e distensão, sendo um risco para a obstrução intestinal. ${ }^{37}$

Entre as possíveis interações, a metilcelulose é capaz de diminuir a ação de suplementos de potássio, diuréticos poupadores de potássio, anticoagulantes orais, digitálicos e salicilatos. O uso crônico deste laxante pode promover também a redução de potássio no sangue. ${ }^{35}$

As fibras sintéticas proporcionam ótima tolerabilidade, rápida ação como incrementadora do bolo fecal e permitem maior adesão ao tratamento, principalmente para os pacientes que apresentam uma alimentação sem qualidade. A apresentação em comprimidos também facilita a ingestão e, conseqüentemente, a adesão ao tratamento.

Quanto às contra-indicações para administração de fibras pode-se citar: a obstrução do intestino, impactação, mudanças nos hábitos intestinais, dificuldade de engolir e abdômen agudo. 38

Tabela 4 - Resumo comparativo entre a lactulose e as fibras sintéticas no tratamento da constipação intestinal de idosos.

\begin{tabular}{ccc}
\hline & Lactulose & Fibras Sintéticas \\
\hline Forma Farmacêutica & Líquida & Sólida \\
Prescrição Diária & Uma ou duas vezes ao dia & $\begin{array}{c}\text { Quatro vezes ao dia associada com } \\
230 \mathrm{~mL} \text { de água a cada ingestão }\end{array}$ \\
Efeitos Colaterais & $\begin{array}{c}\text { Gases que provocam distensão, } \\
\text { inchaço, cólicas abdominais, } \\
\text { eructações e flatulências } \\
\text { Efeito Inicial }\end{array}$ & $\begin{array}{c}\text { Flatulências e cólicas abdominais } \\
\text { menos intensas; obstrução intestinal }\end{array}$ \\
Pacientes Diabéticos & Não horas & 12 a 72 horas \\
\hline
\end{tabular}

\subsection{Custo do Tratamento}

A tabela abaixo lista o custo do tratamento mensal da constipação crônica com diferentes agentes em pacientes idosos. Observa-se que o tratamento com psyllium é mais barato do que o tratamento com lactulose, em contrapartida o tratamento com lactulose tem um custo muito inferior ao tratamento com policarbofila cálcica. 
Tabela 5 - Custo mensal do tratamento da constipação crônica em idosos com laxantes.

\begin{tabular}{cccc}
\hline Fármaco & Nome Comercial & Dose de Administração* & $\begin{array}{c}\text { Custo relativo ao } \\
\text { tratamento mensal }(\mathbf{R} \$)^{26}\end{array}$ \\
\hline \multirow{2}{*}{ Lactulose } & Lactulona Xarope & & $59.25-178.65$ \\
& Pentalac & & $54.85-164.55$ \\
Policarbofila cálcica & Farlac & $10-30 \mathrm{~mL}$ & $59.55-178.65$ \\
& Muvinor & & $57.42-172.26$ \\
Psyllium & & $4-8 \mathrm{~g}$ & $147.84-295.68$ \\
& Metamucil & $10-20 \mathrm{~g}$ & \\
& & & $50.29-100.58$ \\
\hline
\end{tabular}

*BOSSARD Wanda; DREHER Rebeca; SCHNEGG Jean François; BÜLA Cristophe J. The Treatment of Chronic Constipation in Elderly People: an update. Drugs Aging. 2004; 21: 914-915.

\section{JUSTIFICATIVA}

Os idosos particularmente apresentam um risco mais acentuado de desenvolverem constipação crônica, pois com o avanço da idade ocorre atonia ou diminuição do tônus muscular, assim como, os movimentos intestinais diminuem gradativamente, ficando as fezes retidas por um longo período de tempo no reto (retenção fecal). Com isso, o reto passa a conter as fezes, progressivamente mais ressecadas e em maior volume. A parede retal torna-se cronicamente dilatada e a sensibilidade retal diminui; logo, estes indivíduos tornam-se menos responsivos ao estímulo de evacuação.

Contudo, o envelhecimento por si só não causa a constipação; a elevada incidência de constipação na população idosa resulta de uma combinação de fatores de risco, como por exemplo: a ingestão reduzida de líquidos e de fibras; a diminuição na prática de exercícios físicos, doenças crônicas e a utilização de vários medicamentos - polifarmácia. No caso dos idosos acamados e internados deve-se ter uma atenção especial, pois a ausência de atividade e o decúbito prolongado causarão uma diminuição da atividade do intestino grosso.

A elevada prevalência da constipação corresponde a um significativo problema de saúde na população idosa, associada dessa forma, com o prejuízo na sua qualidade de vida. Estudos randomizados com idosos canadenses revelaram que para $11 \%$ dessa população a constipação é considerada o principal problema de saúde. ${ }^{9}$ 
Deve-se levar também em consideração os gastos financeiros, pois os idosos relatam uma proporção substancial de custos com laxantes prescritos e não prescritos, estimados em 43 milhões de euros por ano na Inglaterra, e acima de 500 milhões de dólares por ano nos Estados Unidos. O gasto anual encontrado por meio de estudos americanos realizados com o objetivo de determinar o custo do tratamento da constipação diagnosticada em idosos foi de 2.253 dólares anuais a cada paciente. ${ }^{9,10}$

Assim, faz parte das atribuições do farmacêutico, a promoção da saúde, principalmente através da disposição de um serviço de farmácia com qualidade (e neste aspecto incluem-se a orientação e o acompanhamento farmacêutico). É preciso considerar o potencial de contribuição do farmacêutico e efetivamente incorporá-lo às equipes de saúde a fim de que se garanta a melhoria da utilização dos medicamentos, com redução dos riscos de morbimortalidade e que seu trabalho proporcione meios para que os custos relacionados à farmacoterapia sejam os menores possíveis para a sociedade. ${ }^{8}$

Logo, compreender qual o melhor tratamento para constipação de idosos ao comparar a eficácia, a efetividade e a eficiência do uso de lactulose e das fibras sintéticas é essencial para a promoção da saúde desta população.

\section{OBJETIVO}

\subsection{OBJETIVo GERAL}

Esta monografia tem como objetivo geral realizar uma revisão bibliográfica sobre o problema da constipação nos idosos e suas formas de tratamento, bem como analisar mais detalhadamente duas formas de intervenção específicas: a lactulose e as fibras sintéticas.

\subsection{OBJETIVOS ESPECÍfICOS}

- Ressaltar a importância da contribuição do profissional farmacêutico para a promoção da saúde;

- Definir a patologia constipação intestinal, desde sua fisiopatologia, formas de diagnóstico, causas e epidemiologia;

- Relacionar o processo de envelhecimento ao desenvolvimento da constipação;

- Abordar as formas de tratamento utilizadas para este problema; 
- Detalhar as propriedades particulares da lactulose e das fibras sintéticas;

- Concluir, por meio de análise detalhada, qual o melhor método de intervenção a ser utilizado.

\section{Metodologia}

Considerando todos os aspectos destacados e com o objetivo de identificar e analisar a eficácia, a efetividade e a eficiência da lactulose e das fibras sintéticas a fim de se comparar os seus perfis terapêuticos e, por fim, traçar o melhor tratamento para a constipação em pacientes idosos; foi utilizada a metodologia de pesquisa qualitativa. Tal procedimento metodológico permitiu a avaliação e comparação de dados mundiais de pesquisas realizadas recentemente.

Assim, realizou-se revisão bibliográfica de artigos científicos publicados no período de 1999 a 2009 sobre o tratamento de constipação de idosos com lactulose ou fibras sintéticas na plataforma de periódicos Capes. Para a pesquisa dos artigos foram utilizadas as seguintes palavras chaves: constipação (constipation); idoso (elderly); lactulose (lactulose); policarbofila cálcica (polycarbophil calcium). Assim, foram selecionados para a revisão apenas os artigos que cruzassem duas ou mais dessas palavras.

As análises obtidas foram transcritas na forma de texto e tabelas, e publicadas em forma de trabalho monográfico de conclusão do IV Curso de Especialização em Promoção e Educação para a Saúde, o qual será apresentado para banca de professores da instituição, constituída para este fim. Há expectativa também, para a apresentação deste trabalho em encontros e congressos especializados. Posteriormente pretende-se publicá-lo em forma de artigo. Será enviada também uma cópia do trabalho para o Núcleo de Estudos em Educação, Promoção da Saúde da Universidade de Brasília - NESPROM/UnB.

\section{RESULTADOS}

Na pesquisa bibliográfica foram encontrados ao total 09 artigos sobre o tratamento de constipação de idosos com o uso de lactulose ou fibras sintéticas. Quanto ao tratamento com lactulose foram encontrados especificamente 05 artigos (55\%) e quanto ao tratamento com policarbofila cálcica, 04 (45\%). De forma geral, embora a pesquisa bibliográfica tenha sido realizada entre 1999 a 2009, os artigos concentraram-se no limite de 1999 a 2006. Em adição, 
não foram encontrados artigos nacionais sobre o tratamento de constipação de idosos; logo os artigos selecionados são produções européias, asiáticas e norte-americanas.

Nesta revisão pôde-se constatar a escassez de estudos sobre o tratamento de constipação de idosos. Além do que, não foi encontrada nenhuma pesquisa que realizasse a comparação direta entre o tratamento da constipação de idosos com lactulose e fibras sintéticas. Assim, os artigos selecionados tratam-se de resultados de pesquisas realizadas a partir de um único tratamento (lactulose ou fibras sintéticas), mas esses resultados já permitem realizar inferências quanto à melhor escolha farmacoterapêutica.

Os dados relacionados aos estudos encontrados estão explanados especificamente nos itens 6.1 e 6.2, além disso, uma tabela resumo (Tabela 6) foi elaborada para permitir uma avaliação crítica, rápida e comparativa entre os dois tratamentos.

\subsection{Lactulose}

Attar et al. (1999) realizou três estudos que compararam a lactulose com o placebo: um incluiu pacientes com idade média de 28 anos, outro com idade média superior a 60 anos, e outro com idade média de 84,7 anos. Neste último estudo, a lactulose apresentou resultados superiores ao placebo quanto ao aumento do número de evacuações e uma redução na sensação de tenesmo e de impactação fecal. Pacientes tratados com lactulose apresentaram menos enemas do que os pacientes controle, além do que, não apresentaram nenhum efeito clínico ou laboratorial adverso.

Lederle et al. (1999), constatou que a administração de $30 \mathrm{~mL}$ de lactulose a pacientes idosos com constipação crônica acarretou em um aumento no número de evacuações semanais de 3 para 7. Em outro estudo comparativo entre a lactulose e o sorbitol realizado em uma pequena amostra de 30 pacientes idosos com idade entre 65 e 86 anos foi detectado que ambos apresentaram a mesma efetividade. Contudo, o sorbitol desencadeou menos náuseas do que a lactulose. ${ }^{38}$

Christie et al.(2002) em um ensaio clínico randomizado comparativo entre o polietilenoglicol e a lactulose realizado com 115 pacientes de hospitais geriátricos (idade média de 55 anos, e aproximadamente $45 \%$ com idade superior a 65 anos), durante três meses, verificou que o polietilenoglicol é mais efetivo e tolerado do que a lactulose; porém o seu tratamento foi 2,5 vezes mais oneroso. ${ }^{39}$

Qua et al. (2006) realizou um ensaio clínico randomizado com o intuito de comparar a efetividade da lactulose de das fibras (ispaghula) no tratamento da constipação, esse estudo foi realizado com 39 pacientes de idade média de 50 anos (faixa entre 18-85). Constatou-se 
que a lactulose resultou um aumento maior da frequiência de evacuações $(7,3$ para 8,9$)$ quando comparada às fibras $(5,5$ para 6,5). Dos 39 pacientes que completaram o estudo, $24(61,5 \%)$ preferiram a lactulose e $14(35,9 \%)$ preferiram as fibras. ${ }^{40}$

Em um ensaio clínico randomizado a administração de $20 \mathrm{~mL}$ de lactulose duas vezes ao dia reduziu o tempo de trânsito grastrointestinal em $40 \%$ dos pacientes idosos em tratamento de constipação. Outro estudo aberto comparou lactulose, psyllium e placebo e os resultados comprovaram que os dois agentes são igualmente efetivos no tratamento. E, se comparada com a solução de polietilenoglicol, a lactulose é menos eficaz e tem mais efeitos adversos (Drugdex Drug Evaluations, 2006).

\subsection{Fibras Sintéticas (Policarbofila Cálcica)}

Pallotta et al. (1999) estudou a eficácia clínica da policarbofila cálcica em 57 pacientes de ambos os sexos com idade entre 18 e 57 anos com constipação crônica diagnosticada. Realizou-se um estudo único cego por 8 semanas com o uso de placebo e da policarbofila cálcica. Treze pacientes não completaram o estudo, dos quais oito por razões não relacionadas ao fármaco. Em comparação com o placebo, a policarbofila causou uma redução significativa da consistência das fezes e da força evacuatória. De acordo com o julgamento médico, o fármaco foi "muito bom" em $73 \%$ dos casos, "bom" em $18 \%$ e "não eficaz" em 9\%. Assim, a análise estatística dos dados confirmou a eficácia da policarbofila no tratamento da constipação crônica. ${ }^{45}$

Um grupo de 28 pacientes com idade média de 48 anos foi submetido a um estudo clínico randomizado. Durante 12 semanas uma parte do grupo recebeu $6 \mathrm{~g}$ de policarbofila cálcica enquanto a outra parte recebeu $6 \mathrm{~g}$ de placebo (fosfato de cálcio). Ao final do tratamento, os pacientes tratados com policarbofila cálcica apresentaram uma freqüência de evacuações significativamente superior quando comparado ao placebo (Manu et al. 2002). ${ }^{44}$

Sakakibara et al. (2006) realizou um ensaio clínico aberto, durante 12 semanas, com 4 pacientes de idade média da 53 anos com constipação intestinal diagnosticada. Foi administrada 1,5 g/dia de policarbofila cálcica a cada paciente. Verificou-se que a policarbofila foi tolerada por todos os pacientes e que não foram relatados efeitos adversos. Após o tratamento com a policarbofila, o tempo de trânsito intestinal reduziu de 68,2 horas para 34,6 horas. ${ }^{41}$

Se comparada com a fibra natural, as sintéticas também possuem a vantagem de ter uma ação mais rápida e efetiva. Enquanto o Psyllium aumenta em $10 \%$ a freqüência de 
evacuações, a policarbofila cálcica aumenta esta frequiência em 35\%. Em relação ao volume fecal, o Psyllium proporciona um aumento de $40 \%$, enquanto a policarbofila acarreta um aumento de 65\% no volume das fezes (Drugdex Drug Evaluations, 2006).

Em revisão sistemática realizada por Gallagher et al.(2008), reafirma-se que há poucos estudos sobre o tratamento de constipação dos idosos com a policarbofila cálcica. 
Tabela 6 - Resultados da revisão bibliográfica (1999-2009).

\begin{tabular}{cllll}
\hline Autor & Ano & Participantes & Método de Análise & Resultados \\
\hline
\end{tabular}

\section{Lactulose}

\begin{tabular}{|c|c|c|c|c|}
\hline Attar et al. & 1999 & $\begin{array}{l}\text { Idosos } \\
\text { (Média de } \\
84,7 \text { anos) }\end{array}$ & $\begin{array}{l}\text { Experimental com } \\
\text { placebo. }\end{array}$ & $\begin{array}{l}\text { Aumento no número de } \\
\text { evacuações diárias. }\end{array}$ \\
\hline Lederle et al. & 1999 & Idosos & Experimental. & $\begin{array}{c}\text { Aumento no número de } \\
\text { evacuações semanais de } \\
3 \text { para } 7 .\end{array}$ \\
\hline Christie et al. & 2002 & $\begin{array}{c}\text { Idosos } \\
\text { (Média de } 55 \text { anos) }\end{array}$ & $\begin{array}{l}\text { Experimental: ensaio } \\
\text { clínico randomizado, } \\
\text { por } 3 \text { meses. }\end{array}$ & $\begin{array}{l}\text { Polietilenoglicol mais } \\
\text { tolerado do que a } \\
\text { lactulose. }\end{array}$ \\
\hline Qua et al. & 2006 & $\begin{array}{c}\text { Idosos } \\
\text { (Média de } 50 \text { anos) }\end{array}$ & $\begin{array}{l}\text { Experimental: ensaio } \\
\text { clínico randomizado. }\end{array}$ & $\begin{array}{c}\text { Aumento da freqüência } \\
\text { das evacuações de } \\
7,3 \text { para } 8,9 .\end{array}$ \\
\hline Drugdex Drug & 2006 & Idosos & Não informado & $\begin{array}{l}\text { Redução em } 40 \% \text { no } \\
\text { tempo de trânsito } \\
\text { intestinal. }\end{array}$ \\
\hline
\end{tabular}

\section{Policarbofila Cálcica}

Pallota et al.

1999

Idade entre

18 e 57 anos

Manu et al.

2002

Idosos

(Média de 48 anos)

Sakakibara et al. 2006

Idosos

(Média 53 anos)

Drugdex Drug
Idosos
Experimental: ensaio clínico único cego em 57 pacientes.

Experimental: ensaio clíncio randomizado em

$$
28 \text { pacientes, }
$$
por 12 semanas.

Experimental: ensaio clínico aberto, por 12 semanas.

Não informado
Resultado "muito bom" em $73 \%$ dos pacientes, $18 \%$ "bom", não eficaz em $9 \%$.

Frequência de evacuações superior ao placebo.

Redução do tempo de trânsito intestinal de $68,2 \mathrm{~h}$ para $34,6 \mathrm{~h}$.

Aumento de 35\% na frequiência das evacuações. Aumento de $65 \%$ no volume das fezes. 


\section{DisCuSSÃo E CONCLUSÃo}

A incorporação de fibras à dieta, aliada à realização de exercícios e ao aumento da ingestão de líquido são medidas sugeridas para o tratamento inicial da constipação em idosos. Em um estudo prospectivo com pacientes de idade entre 36 e 61 anos submetidos a exercícios diários e à alta ingestão de fibras constatou que tais pacientes relataram $68 \%$ menos sintomas de constipação quando comparados ao grupo controle; e outras pesquisas americanas prospectivas relataram que a hidratação e a ingestão de fibras reduziram de $91.2 \%$ para menos de $40 \%$ o consumo de laxantes por idosos. Importante ressaltar que nem sempre tais modificações no hábito de vida são possíveis, efetivas e aceitas pelo paciente idoso; logo se torna necessário recorrer ao tratamento farmacológico. ${ }^{33}$

Quanto ao tratamento farmacológico, sabe-se que a prevalência do uso de laxantes em pacientes geriátricos varia entre 11 a 45\%. A prescrição destes para tal população é uma prática comum, embora menos da metade dos pacientes idosos que utilizam laxantes apresentem diagnóstico de constipação. Entre as possibilidades do tratamento farmacológico, os agentes formadores de massa (fibras) e os laxantes osmóticos (lactulose) são recomendados como primeira escolha, mesmo que os dados quanto à eficácia destes sejam limitados. ${ }^{4,8}$

A fermentação da lactulose produz grande quantidade de gás, 10 gramas de lactulose podem originar 1 litro de dióxido de carbono e de hidrogênio gasosos. Boa parte desses gases é absorvida pelo fluxo sanguíneo e exalada. Contudo, pode permanecer no intestino, quantidade de gás suficiente para provocar distensão, inchaço, cólicas abdominais, náuseas, eructações, acidose lática e excesso de flatulência. Logo, em idosos este efeito colateral é um fator limitante para a administração desse agente.

Já as fibras sintéticas predispõem o surgimento de flatulências e cólicas abdominais menos intensas como efeitos gastrintestinais e não possuem outras reações adversas, pois não são absorvidas pelo organismo.

A administração da lactulose pode limitar-se a uma única dose diária, podendo ser administrada com um líquido que agrade o paciente; como se trata de uma forma farmacêutica líquida (xarope) há o risco de ocorrência de aspiração em pacientes idosos. Já as fibras sintéticas são formuladas usualmente sob a forma de tabletes mastigáveis, cuja dose usual é de 4-8 gramas diárias, administrada quatro vezes ao dia, associada a $230 \mathrm{~mL}$ de água a cada tomada. Logo, a administração durante várias vezes no decorrer do dia e a necessidade de ingestão de líquido a cada administração são fatores limitantes quanto à efetividade e adesão ao tratamento, particularmente em pacientes idosos. Essa necessidade de manter boa 
hidratação para prevenir a impactação fecal, torna necessário o monitoramento deste tratamento, principalmente nestes pacientes. Entretanto não é necessário realizar ajustes de dose nos casos de pacientes com insuficiências renal, hepática ou em realização de diálise, pois o fármaco não é absorvido pelo organismo. ${ }^{8,36,42}$

Ao se comparar com a fibra natural, as sintéticas têm uma ação mais rápida e efetiva. Enquanto o psyllium aumenta em $10 \%$ a freqüência de evacuações, a policarbofila aumenta tal freqüência em 35\%; sendo tão eficiente quanto o psyllium no tratamento dos sintomas da constipação em pacientes idosos e causam menor flatulências como efeito colateral. ${ }^{36}$

De forma geral, a lactulose é um laxante seguro e eficaz no tratamento da constipação. Um ensaio clínico randomizado comprovou que a administração de $20 \mathrm{~mL}$ de lactulose duas vezes ao dia reduz o tempo de trânsito intestinal em $40 \%$ nos pacientes idosos; e a administração de $30 \mathrm{~mL}$ de lactulose a idosos com constipação crônica acarretou no aumento de evacuações semanais de 3 para 7. Como tal agente não induz dependência ou tolerância é recomendado a pacientes idosos que requerem longo tempo de tratamento. Em contrapartida, a lactulose não deve ser administrada a idosos diabéticos; pois os dois açúcares - frutose e galactose - constituintes de tal fármaco são liberados ao longo da metabolização da molécula e absorvidos pelo organismo, acarretando no aumento dos níveis glicêmicos. ${ }^{36,42}$

O efeito inicial da lactulose é deflagrado após 24 a 48 horas, já a policarbofila (fibra sintética) possui uma resposta inicial após a ingesta do medicamento ocorrendo em 12 a 72 horas; característica farmacocinética que pode interferir na escolha entre esses agentes laxativos de acordo com o tempo de início de resposta desejado. ${ }^{36}$

Quanto ao custo de tratamento, observa-se que o tratamento com policarbofila cálcica é aproximadamente 2,5 vezes mais caro quando comparado ao tratamento mensal com a lactulose. Assim, pode-se considerar o custo do tratamento como um fator limitante na escolha entre esses dois agentes.

A partir da revisão bibliográfica foi constado que há um maior número de estudos que avaliam a efetividade terapêutica da lactulose quando se comparado com número de pesquisas existentes referentes ao uso da policarbofila cálcica (fibra sintética), considerando o mesmo intervalo de tempo (10 anos). Observou-se ainda que há um número reduzido de pesquisas voltadas para o estudo do tratamento da constipação na população idosa. Além do que, pode se ressaltar que não foi encontrada pesquisa que comparasse diretamente o uso da lactulose e fibras sintéticas no tratamento dos idosos. 
Portanto, os artigos científicos encontrados discutem o uso da lactulose e da policarbofila cálcica na população idosa de forma isolada; mas estas informações possibilitam proporcionar um embasamento teórico para escolha da conduta terapêutica mais adequada.

De forma geral, os estudos experimentais de tratamento da constipação com a lactulose, realizados com idosos no período de 1999 a 2009 demonstram os seguintes resultados: aumento no número de evacuações diárias e semanais, e redução no tempo de trânsito intestinal. E os estudos experimentais de tratamento com a policarbofila cálcica demonstram aumento na freqüência de evacuações, aumento no volume das fezes e redução do tempo de trânsito intestinal.

Diante dos resultados apresentados, pode-se deduzir que ambos agentes laxativos são eficazes e efetivos no tratamento da constipação de idosos. Porém sabe-se que estes pacientes apresentam constipação devido a múltiplos mecanismos fisiopatológicos; conseqüentemente, um agente "universal" para tratamento é improvável. De uma perspectiva farmacológica, o agente ideal deve ter o melhor perfil de eficácia, tolerância, efeitos adversos e interações com outros fármacos. De uma perspectiva de saúde pública, este agente deve também ser efetivo e eficiente.

Então, deve-se avaliar cada paciente idoso de forma isolada, conhecendo primeiramente a sua história clínica, constatar o diagnóstico de constipação e posteriormente escolher a melhor terapêutica de acordo com os efeitos colaterais, o número de administrações diárias, a forma farmacêutica, o custo do medicamento e quanto aos hábitos do paciente; ou seja, deve-se avaliar a probabilidade de adesão do paciente ao tratamento estabelecido a fim de promover a sua saúde.

Em resumo, os dados existentes são limitados quanto ao tratamento de constipação em idosos. Logo, a realização de novas pesquisas é necessária para permitir que o profissional farmacêutico e os demais profissionais de saúde atuem de forma eficaz no tratamento desta patologia. 


\section{REFERÊNCIAS BIBLIOGRÁFICAS}

1. TORTORA, G.J., GRABOWSKI, S.R. Princípios de Anatomia e Fisiologia. 9.ed. Rio de Janeiro: Guanabara Koogan, 2002 (748-749; 786-788).

2. BERNE, R.M., LEVI, M.N.. Fisiologia. Quarta Edição. Guanabara Koorgan. 2000: 579.

3. SILVERTHORN, A.C. Fisiologia Humana. Uma Abordagem Integrada. Segunda Edição. Editora Manole. 2003: 632.

4. Talley NJ.; Fleming KC; Evans JM et al. Constipation in an elderly community: A study of prevalence and potencial risk factors. Am J. Gastroenterol 1996:19-25.

5. GUYTON, A.C., HALL, J.E. Tratado de Fisiologia Médica. Nona Edição. Guanabara Koogan. 1997: $765-766$.

6. HARRISON'S. Principles of Internal Medicine. $15^{\text {th }}$ Edition. McGraw Hill Companies, Inc. 2001: 248-249.

7.LOCKE GR III; PEMBERTON JH; PHILIPS SF. American Gastroenterological Association Medical Position Statement: guidelines on constipation. Gastroenterology. 2000; 119:1761-1766.

8. BOSSARD Wanda; DREHER Rebeca; SCHNEGG Jean François; BÜLA Cristophe J. The Treatment of Chronic Constipation in Elderly People: an update. Drugs Aging. 2004; 21: 914924.

9. MENDES, Gun Bergsten. Uso racional de medicamentos: o papel fundamental do farmacêutico. Departamento de Farmacologia, Faculdade de Ciências Médicas, Universidade Estadual de Campinas. Ciênc. Saúde coletiva; 13 (supl): 569-571, abr. 2008. 
10. VIEIRA, Fabiola Sulpino. Possibilidades de contribuição do farmacêutico para a promoção da saúde. Ministério da Saúde. Ciênc. Saúde coletiva; 12 (1): 213-220, mar. 2007.

11. Organização Pan-Americana de Saúde (OPS). Pautas para establecer políticas farmacéuticas nacionales. Ginebra: OMS; 1988.

12. Lei Federal $n^{\circ} 5.991$, de 17 de dezembro de 1973. Dispõe sobre o controle sanitário do comércio de drogas, medicamentos, insumos farmacêuticos e correlatos, e dá outras providências. In: Conselho Regional de Farmácia do Estado de São Paulo. Legislação para o farmacêutico. São Paulo: CRF-SP; 1996. p.22-33.

13. FLOWER R. Lifestyle drugs: pharmacology and the social agenda. Trends in Pharmacological Sciences 2004; 25: 182-5.

14. BARROS JAC. Propaganda de medicamentos: atentado à saúde? São Paulo: Hucitec /Sobravime; 1995.

15. LEXCHIN J. Uma fraude planejada: a publicidade farmacêuticano terceiro mundo. In: Bonfim JRA, MercucciVL. A construção da política de medicamentos. São Paulo: Hucitec/Sobravime; 1997. p.269-289.

16. ZUBIOLI A. A farmácia clínica na farmácia comunitária. Brasília: Ethosfarma; 2001.

17. Secretaria de Estado de Saúde de São Paulo (SESSP). Centro de Vigilância Sanitária. Programa de Farmacovigilância. Farmacovigilância: ação na reação. São Paulo: SES; 2002. 
18. Sociedade Brasileira de Vigilância de Medicamentos (Sobravime). O que é uso racional de medicamentos. São Paulo: Sobravime; 2001. p.50-56.

19. MARÍN N, et al., organizadores. Assistência farmacêutica para gerentes municipais de saúde. Rio de Janeiro: OPAS/OMS; 2003. p. 239-286.

20. FERRAES AMB, CORDONI Jr L. Medicamento, farmácia, farmacêutico e o usuário: novo século, novas demandas; 2003. [documento da Internet]. [acessado 2003 Ago 03]. Disponível em: <http://www.ccs.uol.br/ espacoparasaude/v4n1/doc/farmacia.doc

21. MARTINS, MCFN. Humanização da assistência e formação profissional. In: Secretaria Municipal da Saúde de São Paulo. Área Temática de Assistência Farmacêutica. Termos de Referência da I Conferência Municipal de Política de Medicamentos e Assistência Farmacêutica. São Paulo; 2002.

22. LENNARD-JONES JE. Clinical management of constipation. Pharmacology 1993 Oct; 47 (Suppl 1).

23. WHITEHEAD WE. Psychosocial aspects of functional gastrointestinal disorders. Gastroenterol Clin North Am 1996 Mar.

24. Manual Merck de Informação Médica. Merck Research Laboratories. 2005: Seção 9, cap.107.

25.SCHAEFER, D.C. Constipation in the elderly. Am Fam Physician, 1998 Sep 15.

26. MELO, M.C.B., GUIMARÃES, E.V., TORRES, M.R.F., STEINER, S.A., FIGUEIREDO, R.C.P., PENNA, F.J. Constipação intestinal. Faculdade de Medicina - UFMG. 
27. WHITEHEAD, W.E., WALD, A., DIAMANT, N.E., ENCK, P., PEMBERTON, J.H., RAO, S.S.C. Functional disorders of the anus and rectum. Guts. V.45, supl. II. p.1155-1159, 1999.

28. THOMPSON WG, LONGSTRETCH GF, DROSSMAN DA, et al. Functional bowel disorders and functional abdominal pain. Gut. 1999; 45(suppl. 2):II43-II47

29. Stwart RB; Moore MT; Markes RG et al. Correlates of constipation in an ambulatory elderly population. Arn J Gastroenterol 1992; 87:859-64.

30. WALD A.; VAN Thiel DH; HOECHSTETTER L et al. Gastrointestinal transit: The effect of the menstrual cicle. Gastroenterology 1981;80:1497-500.

31. CHERIYL Phillips; DAVID Polakoff; SUSAN K.; ROBERT Mauch Assessment of Constipation Management in Long Term Care Patients

32. SIMMY B. The cost of Constipation in the Institutionalized Elderly. American Medical Directors Association.

33. JANICE RN.; MARION E. Review of the literature on constipation to enable development of a constipation risk assesment scale. Journal of Orthopaedic Nursing 2004,192-207.

34. NYAM, D.C., PEMBERTON, J.H. Current advances and controversies in the surgical therapy for anorectal motility disorders. Dig Dis 1997; 15 (Suppl 1).

35. Guia dos Remédios. Sétima Edição. 2005.

36. Drugdex Drug Evaluations 
37. ATTAR A, LEMANN M, FERGUSON A, et al. Comparison of a low dose polyethylene glycol electrolyte solution with lactulose for treatment of chronic constipation. Gut 1999; 44: 226-30.

38.LEDERLE FA, BUSCH DL, Mattox KM, et al. Cost-effective treatment of constipation in the elderly: a randomised double-blind comparison of sorbitol and lactulose. Am J Med 1999; 89: 597-601.

39.CHRISTIE AH, CULBERT P, GUEST JF. Economic impact of low dose polyethylene glycol 3350 plus electrolytes compared with lactulose in the management of idiopathic constipation in the UK. Pharmacoeconomics 2002; 20 (1): 49-60.

40.H.M. Quah, B.S. Ooi, SEOW Choen F., SNG K.K., HO K.S. Prospective randomized crossover trial comparing fibre with lactulose in the treatment of idiopathic chronic constipation. Tech Coloproctol. (2006) 10:111-114.

41.SAKAKIBARA Ryuji, YAMAGUCHI Taketo, UCHIYAMA Tomoyuki, LIU Zhi, YAMAMOTO Tatsuya, ITO Takashi, ODAKA Takeo, HATTORI Takamichi. Calcium polycarbophil improves constipation in non-traumatic spinal cord disorders. Clin Auton Res (2006) 16:289-292.

42. Martindale - The Complete Drug Reference

43.VANNESS M.; GURNEY M. Handbook of gastrointestinal drug therapy. Boston: Little Brown and Company; 1989.

44.MANU Peter. The pharmacotherapy of commom functional syndromes. The Haworth Medical Press; 2000.

45. Pallotta N, Rubinetto MP, Zaccaro C, Gizzi G, Villani V, Barbara L. Calcium polycarbophil in clinical practice. The therapy of constipation. Minerva Gastroenterol Dietol (1999) Dec; 39 (4):175-8. 